\title{
Optimization of proton exchange membrane fuel cell's end plates
}

\author{
Mostafa Habibnia ${ }^{1} \cdot$ Mohammadreza Shirkhani $^{2} \cdot$ Peyman Ghasemi Tamami ${ }^{3}$
}

Received: 1 December 2019 / Accepted: 4 July 2020 / Published online: 15 July 2020

(c) Springer Nature Switzerland AG 2020

\begin{abstract}
In this study, we present the optimization of end plates to produce uniform pressure and low content on the gas diffusion layer in polymer membrane fuel cell. For this purpose the end plates and the influence of parameters on the gas diffusion layer pressure has been investigated. Parameters studied are the thickness of the end plate, the depth of the bipolar plates groove and the clamping pressure applied to the end plates. After defining their values in the Abaqus finite element software, mechanical analysis has been carried out to examine the stress distribution on the gas diffusion layer and the results have been extracted. By extracting the results of the analysis and importing into the Adaptive Network-based Fuzzy Inference Systems in MATLAB software, a numerical relationship between the influential values and the outputs is extracted. By investigating these relationships and defining the objective function, we investigate the algorithm required for the equation and uniformity of stress distribution on the gas diffusion layer. In this research, the bee algorithm has been used and it has been evaluating the effective parameters of the optimum fuel cell state. After final review of the results, the suggested optimum state of the bee algorithm is the thickness of the end plate $12 \mathrm{~mm}$, the depth of the bipolar plate groove is $0.1077 \mathrm{~mm}$ and the clamping pressure is $11.0199 \mathrm{MPa}$.
\end{abstract}

Keywords PEM fuel cell · End plate · Optimization · Bee algorithm

\section{Introduction}

Today, the use of fossil fuels is limited due to their limited and harmful effects on the environment. Therefore, the use of new and renewable energy has been considered by all. The fuel cell is one of the most popular energy sources. The basis of fuel cells is the reaction between oxygen and hydrogen and the production of electrical energy. Proton Exchange Membrane fuel cells are one of the most practical types of fuel cells in the industry. The power density of this type of fuel cell is higher than other types of fuel cell [1-3]. Therefore, it is very important to identify the parts and study how they work and try to optimize the efficiency of the fuel cell. In this study PEM ${ }^{1}$ fuel cells have been investigated. PEM fuel cell's Components such as MEA, GDL ${ }^{2}$ and bipolar plate should be put together with the proper contact pressure from end plates to avoid the leakage and also to minimize the contact resistance of the cells [4-6]. Many studies have been done in the area of investigation of fuel cell's end plates and it's components

\footnotetext{
1 Proton Exchange Membrane.

2 Gas Diffusion Layer.
}

\footnotetext{
$\triangle$ Mostafa Habibnia, m.habibnia@jouybariau.ac.ir | 'Department of Mechanical Engineering, Jouybar Branch, Islamic Azad University, Jouybar, Iran. ${ }^{2}$ Department of Mechanical Engineering, Sari Branch, Islamic Azad University, Sari, Iran. ${ }^{3}$ Department of Mechanical Engineering, Tarbiat Modares University, Tehran, Iran.
} 
to optimize efficiency. Ghasemi and et al. [1] have studied PEM fuel cell's electrical and mechanical behavior to optimize its efficiency. Ghasemi and et al. [2] have studied the sealing gasket of PEM fuel cells to optimize the efficiency.

The pressure distribution on the GDL is highly dependent on the end plates. With regard to the past research, end plate material, end plate thickness, end plate dimensions, load condition, clamping pressure, area of force, number of bolts and the position of the clamping bolts influence the distribution of pressure on $\operatorname{GDL}[7,8]$. The purpose of the proposed method is to design a fuel cell using the bee algorithm in order to achieve a uniform pressure distribution on GDL, in which the end plates have a great effect. In order to achieve these goals, hypotheses have been defined. Using the ANFIS, ${ }^{3}$ the relationship between the fuel cell parameters and the amount of pressure distribution on the end plates is modeled by the ANFIS. To do this, the data obtained from the experiment in different conditions have been used. Using the bee algorithm and based on the use of the built-in ANFIS, the best values of the fuel cell parameters are selected so that the pressure distribution is completely uniform and the weight reaches its lowest value. The role of end plates is putting different pieces of fuel cells together. A pressure force on end plates creates contact between all PEM components. The end plates of the fuel cells are deformed under the clamping force. The extent of deformation is an effective parameter on pressure distribution. So that less deformation will cause a more uniform pressure distribution $[9,10]$. Lee studied distribution of pressure in a sample and only looked at the effect of different torque forces on the pressure distribution and did not examine other parameters [11]. Liu examined screw position in a square case with fixed dimensions. The number and size of the screws have not been examined and the research is not complete [12]. Asghari has examined the thickness of the end plates. In this research, the other the parameters such as number and position of the screws have not been studied [13]. Past research on end plates has not been comprehensive, and there is no codified record of higher productivity through uniform pressure distribution. For example, for a GDL in a fuel cell with a constant power and constant active area, designing an end plate that can generate the most efficiency is not available. As mentioned, research is needed to reach endplates design that can be economically viable in addition to high efficiency.

An assembled PEM fuel cell stack and all components are shown in Fig. 1. As seen, this model includes an end plate, Copper plate, a gasket between bipolar plate and Copper plate, a bipolar plate and a GDL.

The generalities of the research are presented first, and in the continuation of the discussion, a brief history of the research conducted on the subject of research and their results is examined and the required understanding including bee algorithm and inventory has been introduced. In the next section, the proposed method is introduced. After that, the results obtained by the prediction method are presented and in the last section, a conclusion is given.

\section{Methods}

Based on the simulations performed and the results obtained, it is found that the end plate with eight bolts is considered with intervals and its parameters have the best output and therefore the analysis has been done with these conditions. In the proposed method the bee algorithm has been used in order to find the optimum values of the plate thickness, bipolar plate groove depth and clamping force. In order to apply bolt pressure to the end plates in the Load module in the Abaqus software, pressure is applied to the desired part. For this purpose, the part of the screw head by which the pressure is applied is partitioned on the end plate and the pressure is applied to the area. These defined parameters on simulated fuel cell have been shown in Fig. 2 .

The overall structure of the proposed method has been shown in Fig. 3. The proposed method consists of two parts that in the first section, based on the data obtained from the experiments under different conditions, the relationship between the various values of the parameters and the deviation in the distribution of pressure has been found. For this matter ANFIS in MATLAB software has been used. For this purpose, geometric parameters were used with different values as the input of ANFIS and the deviation value in the pressure distribution was used as the output. ANFIS should be able to detect the relationship between the hydrodynamic parameters and the deviation in the pressure distribution with the minimum error.

After that the desired ANFIS were made, Using the bee algorithm, we look for values of the geometric parameters that cause the least deviation of pressure distribution on $\mathrm{GDL}$. The proper definition of the target function is one of the most important parts in each issue of optimization. In the proposed method, the deviation of pressure and weight distribution is used in the definition of the target function. They should be examined based on their weight values to

\footnotetext{
3 Adaptive Network-based Fuzzy Inference Systems. 


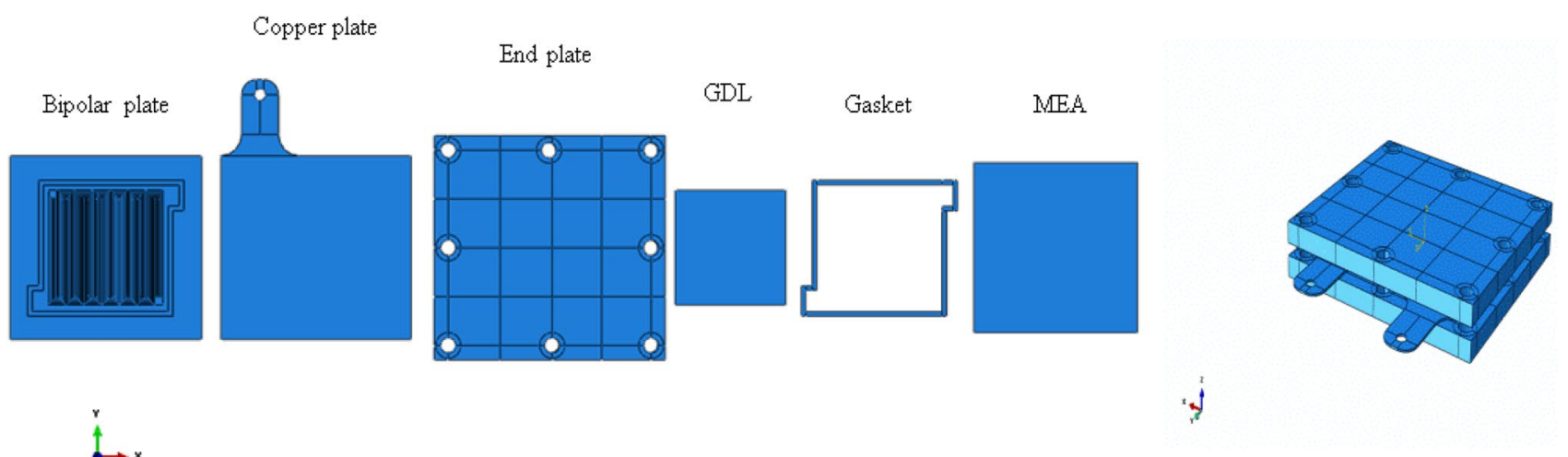

Fig. 1 Assembled and all components of one stack PEM fuel cell [1]
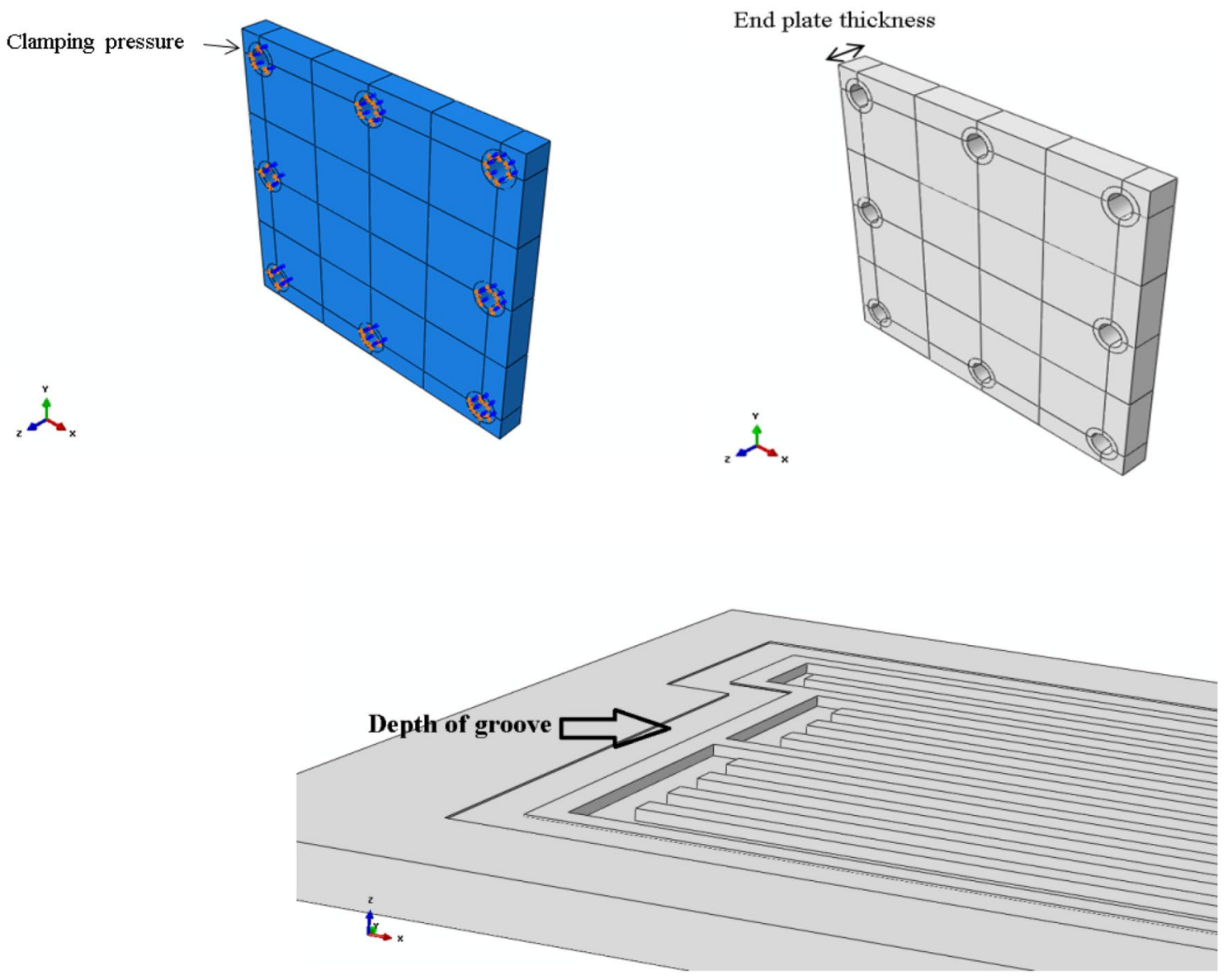

Fig. 2 Defined parameters for fuel cell

determine their effects. The mathematical definition of the target function is shown by Eq. (1) and shows the effective parameters and their magnitude of impact using weighting coefficients.

Fitness $=\mathrm{w}_{1} \times$ Deviation $+\mathrm{w}_{2} \times$ Weight
The bee algorithm must be able to find the values of the geometric parameters to minimize the amount of the target function. In the second part of the proposed method, the bee algorithm searches for the values of the geometric parameters and uses the ANFIS constructed in the previous section to evaluate the responses. The answer leading 


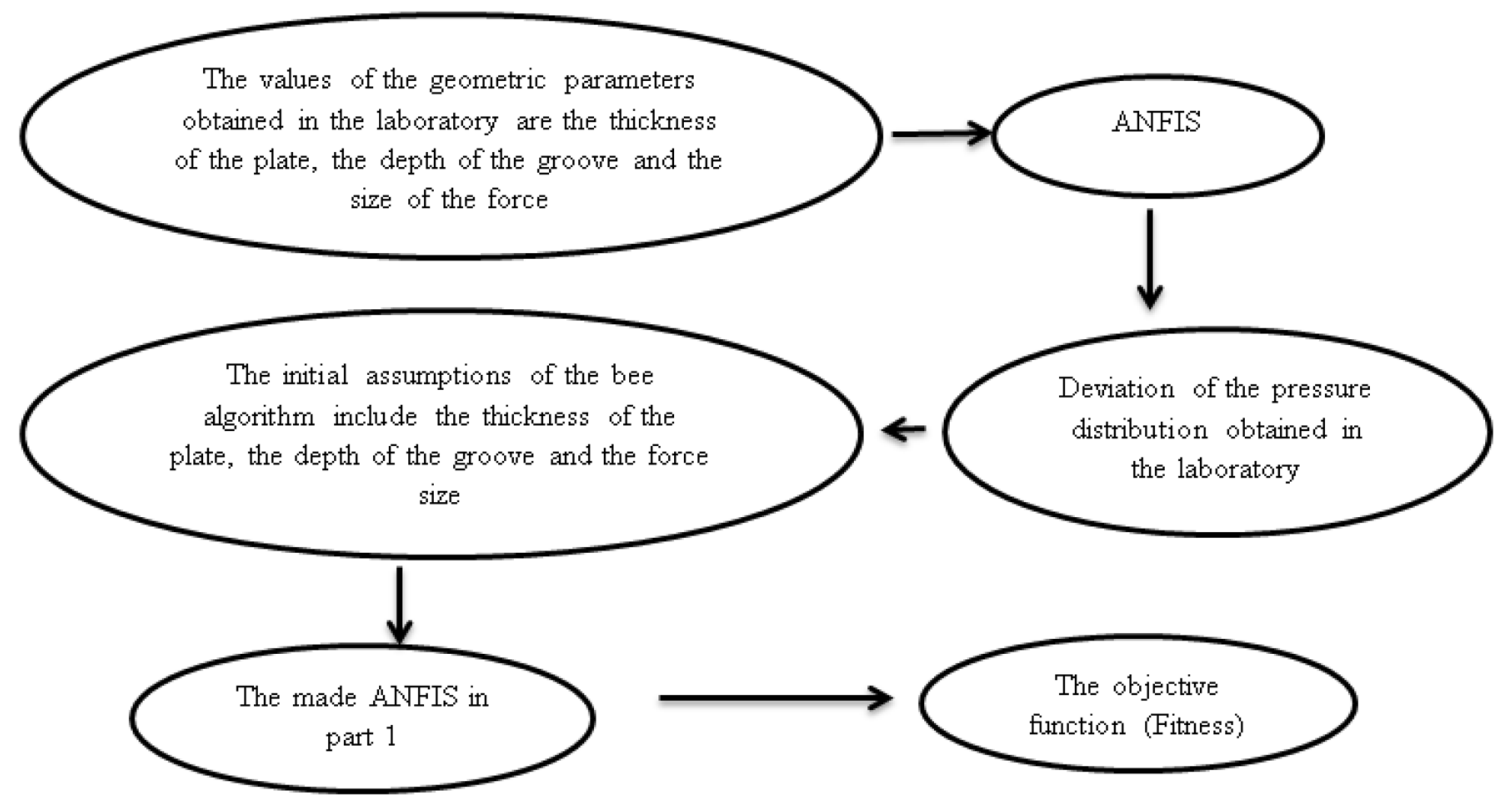

Fig. 3 General structure of the proposed system

to the lowest value of the target function is chosen as the perfect answer.

\section{Results}

In this section, the results are presented using the proposed method. This section has two parts.

\subsection{ANFIS function without optimization}

In the first part of the research, using the data obtained in the experiments, the envelope is constructed. The change ranges and other parameters of the experiment are shown in Table 1.

In this experiment, ANFISES are used as a classifier. Also, ANFIS parameters such as the type of membership functions and the radius value are selected with the try and error. The results using different membership functions have been shown in Table 2 . In these simulations, the Sugeno fuzzy inference engine and the Gaussian membership function have been used. This test shows the effect of radius on the performance of the system. As can be seen from the Table 2, there is no direct correlation between the radius values and the accuracy of the system. In the conducted experiment with increasing radius of 0.1 , the accuracy of the system became better, and at the radius 0.4 it reached its highest value equal 0.53 . From radius of 0.4 , the precision of the system is reduced to a maximum precision, and many fluctuations are shown. In ANFIS, the number of membership functions and fuzzy rules has a photographic relationship with the radius value. If the radius parameter has a small value, the number of fuzzy rules and membership functions increases, conversely, if the radius is large, the number of membership functions and fuzzy rules will be reduced. Of course, there is no relationship between the number of membership functions and the accuracy of the system and for the best performance, its high value should be found.

In the next step, to evaluate the effect of the type of membership functions, the membership functions mentioned in the previous sections are used. The results of this step are shown in the Table 3. The parameters of the membership functions are selected with trial and error and based on the best obtained accuracy.

Table 4 describes the effect of changing parameters on system performance. For this purpose, two Gaussian and triangular membership functions have been used. In Gaussian membership function $\mathrm{c}_{1}$ and $\sigma_{1}$ and in the triangular membership function, the parameters $a, b$ and $c$ must be set. The results show that different values of the

Table 1 Input parameter values

\begin{tabular}{lll}
\hline Row & Parameter & Value \\
\hline 1 & Bolt number & 8 \\
2 & End plate material & Steel \\
3 & Stress on GDL (MPa) & {$[10-12]$} \\
4 & End plate thickness $(\mathrm{mm})$ & {$[8-12]$} \\
5 & Groove depth $(\mathrm{mm})$ & {$[0.1-0.15]$} \\
\hline
\end{tabular}


Table 2 The values obtained for a different radius

\begin{tabular}{lll}
\hline Run number & Radius & $\mathrm{MSE}^{\mathrm{a}}$ \\
\hline 1 & 0.1 & 0.76 \\
2 & 0.2 & 0.63 \\
3 & 0.3 & 0.69 \\
4 & 0.4 & 0.53 \\
5 & 0.5 & 0.88 \\
6 & 0.6 & 0.68 \\
7 & 0.7 & 0.76 \\
8 & 0.8 & 0.82 \\
9 & 0.9 & 0.62 \\
10 & 1 & 0.73 \\
\hline
\end{tabular}

${ }^{\mathrm{a}}$ Mean square error parameters result in different results. The results of these studies indicate the necessity of accurate selection of the parameters of the fuzzy system membership function.

ANFIS operation before optimization has been shown in Fig. 4. In this figure, the blue line indicates the actual value of the deviation of the pressure obtained in the experiments and the red line indicates the fuzzy output. As shown in Fig. 4, ANFIS error in the prediction of the standard deviation is small. This error of operation can cause large errors in practice. Therefore, we should look for a solution that will increase the accuracy of the ANFIS.

\subsection{ANFIS function after optimization}

In this section, the function of the proposed method is examined. In the proposed method, the bee algorithm is used to find the optimal radius vector [14-16]. In the next phase of the envelope, the bee algorithm is used to find the values of the parameters. Because of the importance of uniformly distributed pressure, the value of the weight function used for pressure deviation in the target function equation is considered to be greater than the weight function of the weight. The results obtained for the design of ANFIS are listed in Table 6. In this Table, the radius vector value is obtained using the bee algorithm. To do this,
Table 4 Investigation of the effect of parameter change on system performance

\begin{tabular}{llll}
\hline $\begin{array}{l}\text { Gaussian membership } \\
\text { function parameters }\end{array}$ & MSE & $\begin{array}{l}\text { Triangular membership } \\
\text { function parameters }\end{array}$ & MSE \\
\hline$\sigma_{1}=1, c_{1}=4$ & 0.56 & $\mathrm{a}=3, \mathrm{~b}=5, \mathrm{c}=9$ & 0.75 \\
$\sigma_{1}=2, \mathrm{c}_{1}=4$ & 0.6 & $\mathrm{a}=2, \mathrm{~b}=5, \mathrm{c}=9$ & 0.83 \\
$\sigma_{1}=2, c_{1}=5$ & 0.53 & $\mathrm{a}=3, \mathrm{~b}=5, \mathrm{c}=8$ & 0.88 \\
$\sigma_{1}=2, \mathrm{c}_{1}=4$ & 0.63 & $\mathrm{a}=3, \mathrm{~b}=6, \mathrm{c}=9$ & 0.72 \\
$\sigma_{1}=3, \mathrm{c}_{1}=5$ & 0.77 & $\mathrm{a}=2, \mathrm{~b}=6, \mathrm{c}=9$ & 0.81 \\
\hline
\end{tabular}

the algorithm was executed 10 times and their output was listed in the Table 5. In simulations, ANFIS had the best accuracy with the Gaussian membership function. So in the Table 6, the results obtained are related to this kind of membership function. As you can see, the bee algorithm can find the best amount of radius each time, and make ANFIS with the best accuracy (the minimum error).

By using the proposed method, the number of experiments can be cured and achieved at a lower cost to the desired values.

ANFIS operation before optimization has been shown in Fig. 5. In shown figure, the blue line indicates the actual value of the deviation of the pressure obtained in the experiments and the red line indicates the fuzzy output. According to the figure, it is known that after the optimization, the ANFIS has a good accuracy and the results have been well suited to the results of the target function.

\section{Discussion}

As stated, the weight of the end plates in the PEM fuel cells is a very important parameter [16-18]. For this reason reducing the weight on the end plates is important
Table 3 Results obtained using different membership functions

\begin{tabular}{lllll}
\hline $\begin{array}{l}\text { System } \\
\text { number }\end{array}$ & $\begin{array}{l}\text { Membership } \\
\text { function }\end{array}$ & Membership function parameters & Fuzzy inference engine & MSE \\
\hline 1 & Sugeno & $\mathrm{a}=2, \mathrm{c}=4$ & Sigmoid & 0.61 \\
2 & Sugeno & $\sigma_{1}=2, \mathrm{c}_{1}=5$ & Gaussian & 0.53 \\
3 & Sugeno & $\mathrm{a}=2, \mathrm{~b}=4, \mathrm{c}=6$ & Bell-shaped & 0.69 \\
4 & Sugeno & $\mathrm{a}=1, \mathrm{~b}=4, \mathrm{c}=5, \mathrm{~d}=10$ & $\pi$ shape & 0.71 \\
5 & Sugeno & $\mathrm{a}=1, \mathrm{~b}=8$ & S shape & 0.58 \\
6 & Sugeno & $\mathrm{a}=1, \mathrm{~b}=5, \mathrm{c}=7, \mathrm{~d}=8$ & Trapezoidal shape & 0.66 \\
7 & Sugeno & $\mathrm{a}=3, \mathrm{~b}=6, \mathrm{c}=9$ & Triangular shape & 0.72 \\
8 & Sugeno & $\mathrm{a}=2, \mathrm{~b}=5$ & Z shape & 0.65 \\
\hline
\end{tabular}


Fig. 4 ANFIS function before optimization

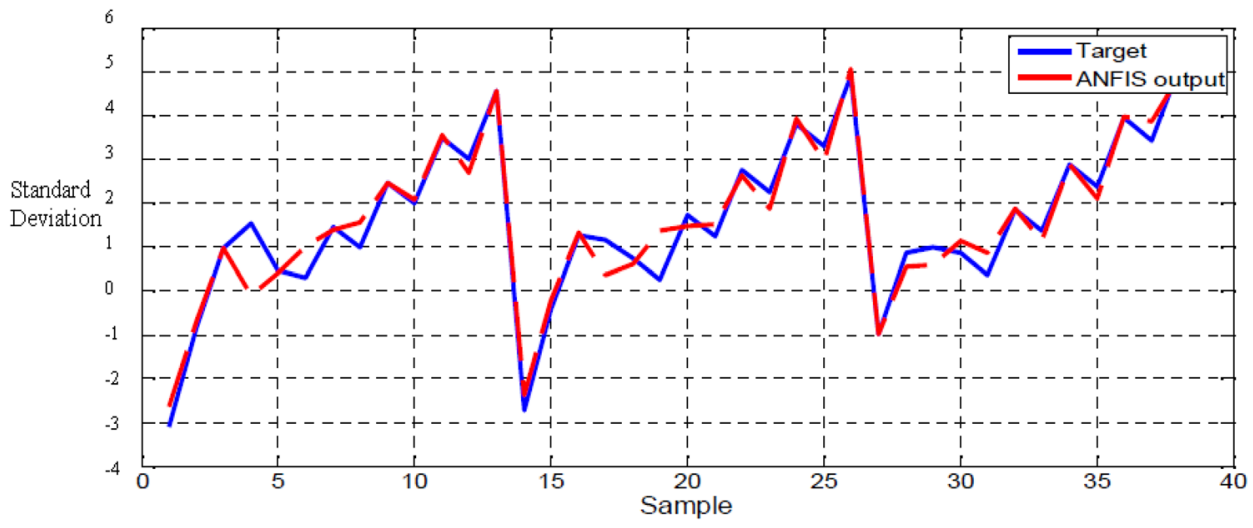

Table 5 The results of the proposed method for designing the envelope

\begin{tabular}{lll}
\hline Row & $\begin{array}{l}\text { Membership } \\
\text { function }\end{array}$ & MSE \\
\hline 1 & Gaussian & 0.0015 \\
2 & Gaussian & 0.0015 \\
3 & Gaussian & 0.0015 \\
4 & Gaussian & 0.0015 \\
5 & Gaussian & 0.0015 \\
6 & Gaussian & 0.0015 \\
7 & Gaussian & 0.0015 \\
8 & Gaussian & 0.0015 \\
9 & Gaussian & 0.0015 \\
10 & Gaussian & 0.0015 \\
\hline
\end{tabular}

of the groove creates a uniform and optimal stress on the GDL. Optimal proposed geometric structure of the end plate has been shown in Fig. 6 .

According to the proposed model of the end plate in Abaqus software and the previous proposed model by the bee algorithm, the value of the distribution of pressure has been evaluated, the results of which are shown in the Fig. 7.

The results shown in the Fig. 7 indicate that by changing the geometry of the end plates to the geometry defined in the Fig. 6, maintaining the values given in the bee algorithm, the maximum stress levels generated on the end plates will be reduced.

\section{Conclusion}

Table 6 Parameters values after optimization

\begin{tabular}{lll}
\hline Row & Parameter & Value \\
\hline 1 & Bolt number & 8 \\
2 & Plate material & Steel \\
3 & Minimum stress on GDL & {$[10-12]$} \\
4 & Plate thickness & 12 \\
5 & Groove depth & 0.1077 \\
6 & Stress & 11.0199 \\
7 & W $_{1}$ & 9 \\
8 & W $_{2}$ & 1 \\
9 & Standard deviation & 0.2503 \\
\hline
\end{tabular}

for designing them. In this study after finding the optimal parameters for the end plate in the PEM fuel cell as shown in Table 6, geometric shape of the end plate is investigated to provide uniform stress and lower weight in the fuel cell structure. This has been done in the Abaqus optimization environment. After defining the problem for Abaqus, the proposed model for the Abaqus software is presented in the Fig. 6. This model, in addition to low weight, has the required rigidity. This shape of end plates with the same optimal values of thickness, clamping force and the depth
This study examines optimization of proton exchange membrane fuel cell's end plates. The questions raised in this regard are whether the proposed method can achieve uniform pressure distribution according to the design criteria for the end plates of the fuel cell. How the proposed method can be lighter in weight according to the design criteria for the end pages of the application. How the proposed method can increase the accuracy of existing methods. In order to achieve these questions, hypotheses have been defined. Using the ANFIS, the relationship between the fuel cell parameters and the amount of pressure distribution on the end plates is modeled by the ANFIS. Using the bee algorithm and based on the use of the built-in ANFIS, the best values of the fuel cell parameters are selected so that the pressure distribution is completely uniform and the weight reaches its lowest value. Based on the simulations, a three-dimensional model of polymer membrane fuel cell is modeled in the software. By ANFIS, quantitative relations between the output and input parameters have been extracted. As shown in Tables 2, 3, 4 , based on the Bee algorithm used in the research and according to the attempt and error in the research, the 
Fig. 5 ANFIS function after optimization

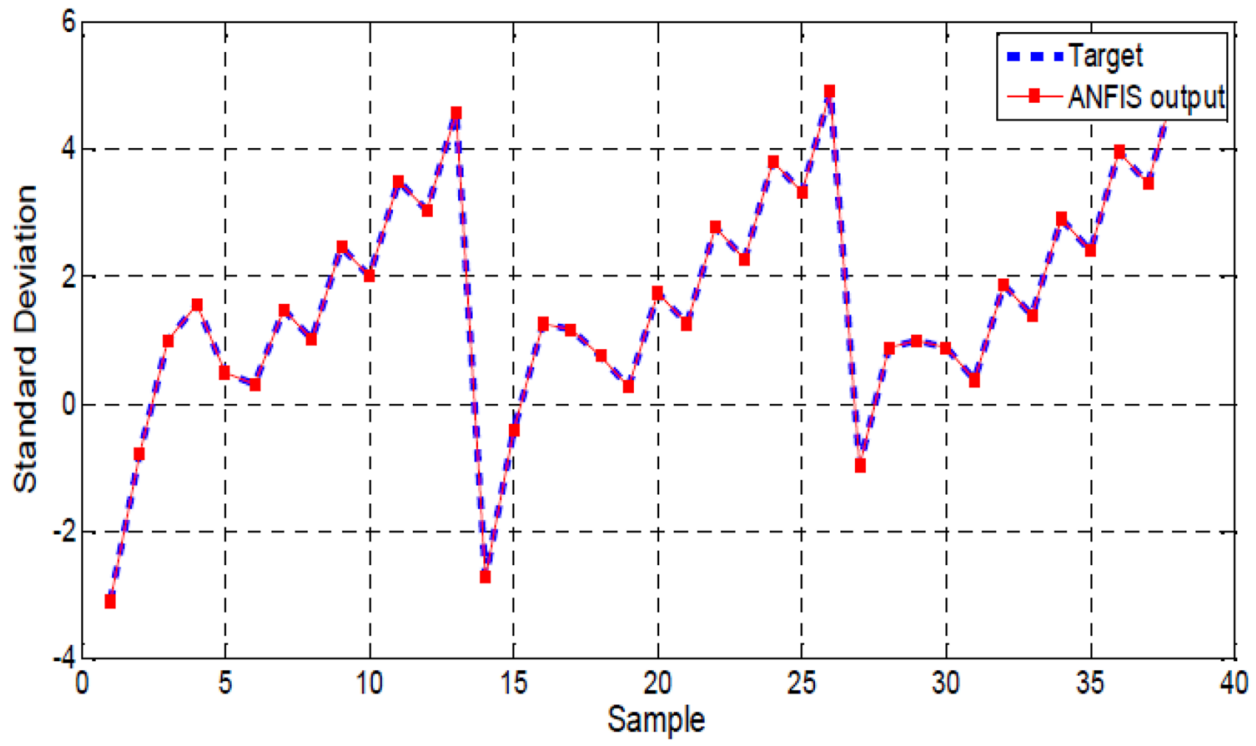

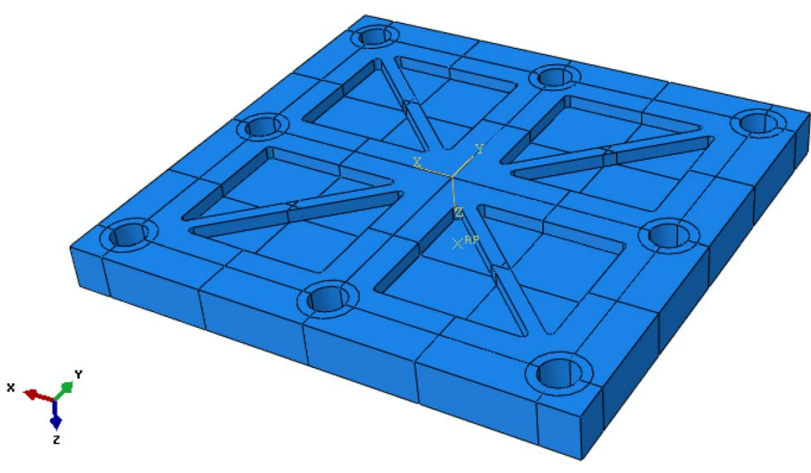

Fig. 6 Optimal proposed geometric structure of the end plate radius of curvature 0.4 and the Gaussian performance function have the minimum error and are selected for optimization. As shown in Table 6, the suggested optimum state of the bee algorithm is the thickness of the end plate $12 \mathrm{~mm}$, depth of the bipolar plate groove is $0.1077 \mathrm{~mm}$ and the clamping pressure on end plate is $11.0199 \mathrm{MPa}$. At the end of the study, the selected model in the Bee algorithm has been introduced into the Abaqus software. According to Figs. 6 and 7, based on the proposed Abaqus model, the model with a $40 \%$ Rib has minimum stress applied to the GDL and is the best model for the cell. Due to the theoretical nature of this research and working with
Fig. 7 Maximum stress on GDL with different end plates

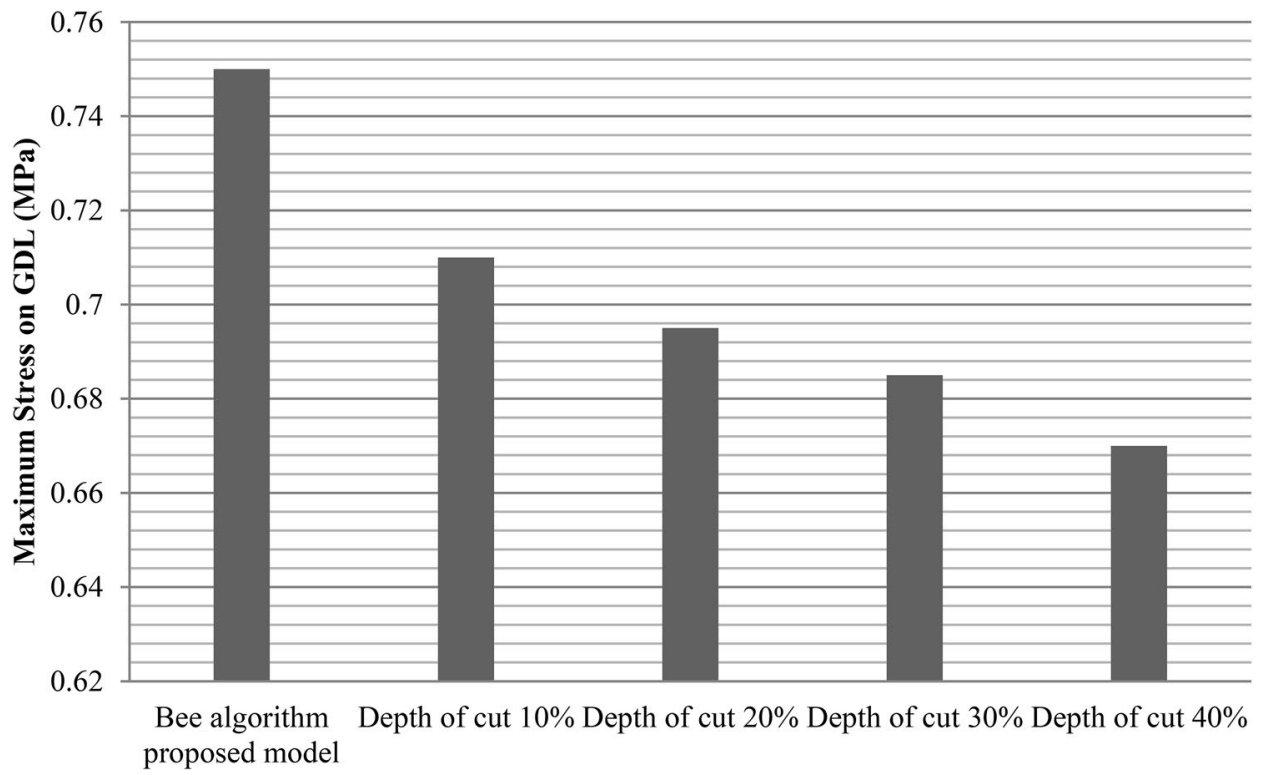

SN Applied Sciences 
the software, there are limitations in the practical observation of the results, and this project can continue in the experimental phase. As a suggestion to continue working, we can work on optimizing the structure of the gaskets in the fuel cells, and the geometry of these gaskets can be optimized so that the fuel cell is optimized in terms of sealing. Another example of the proposed work to continue the research is the study of the material of the end plates used in the cells in the experimental section, and for this purpose, it is possible to research the end plates of composite materials.

\section{Compliance with ethical standards}

Conflict of interest The authors declare that they have no conflict of interest.

\section{References}

1. Habibnia M et al (2016) Investigation and optimization of a PEM fuel cell's electrical and mechanical behavior. Iran J Hydrogen Fuel Cell 3(1):1-10

2. Fili MH, Habibnia M, Ghasemi Tamami P (2017) Modeling and experimental study on the sealing gasket of proton exchange membrane fuel cells. Iran J Hydrogen Fuel Cell 3(3):213-220

3. Habibnia M, Ghasemi Tamami P, Sang Davini H (2018) Design and investigation of honeycomb end plates for PEM fuel cells. Iran J Hydrogen Fuel Cell 4(3):189-199

4. Kim JG et al (2015) Autocorrelation standard deviation and root mean square frequency analysis of polymer electrolyte membrane fuel cell to monitor for hydrogen and air undersupply. J Power Sour 300:164-174

5. Ham S-W et al (2015) A simplified PEM fuel cell model for building cogeneration applications. Energy Build 107:213-225

6. Jang $\mathrm{H}$ et al (2015) Direct power generation from waste coffee grounds in a biomass fuel cell. J Power Sour 296:433-439
7. Bates A et al (2013) Simulation and experimental analysis of the clamping pressure distribution in a PEM fuel cell stack. Intern J Hydrogen Energy 38(15):6481-6493

8. Xing XQ et al (2010) Optimization of assembly clamping pressure on performance of proton-exchange membrane fuel cells. J Power Sour 195(1):62-68

9. Yim S-D et al (2010) The influence of stack clamping pressure on the performance of PEM fuel cell stack. Curr Appl Phys 10(2):S59-S61

10. Carral C, Mélé P (2014) A numerical analysis of PEMFC stack assembly through a 3D finite element model. Int J Hydrogen Energy 39(9):4516-4530

11. Lee S-J, Hsu C-D, Huang C-H (2005) Analyses of the fuel cell stack assembly pressure. J Power Sour 145(2):353-361

12. Lai $X$, Peng L, Ni J (2008) A mechanical-electrical finite element method model for predicting contact resistance between bipolar plate and gas diffusion layer in PEM fuel cells. J Power Sour 182(1):153-159

13. Asghari S, Shahsamandi MH, Ashraf Khorasani MR (2010) Design and manufacturing of end plates of a $5 \mathrm{~kW}$ PEM fuel cell. Intern J Hydrogen Energy 35(17):9291-9297

14. Pham DT et al (2006) *The bees algorithm - a novel tool for complex optimisation problems. In: Intelligent production machines and systems, 2nd I*PROMS virtual international conference 3-14 July 2006, pp 454-459

15. Gholipour R, Khosravi A, Mojallali H (2015) Multi-objective optimal backstepping controller design for chaos control in a rod-type plasma torch system using bees algorithm. Appl Math Model 39(15):4432-4444

16. Sarailoo M, Rahmani Z, Rezaie B (2015) A novel model predictive control scheme based on bees algorithm in a class of nonlinear systems: application to a three tank system. Neurocomputing 152:294-304

17. Stein T, Ein-Eli Y (2019) Proton exchange membrane (PEM) fuel cell bipolar plates prepared from a physical vapor deposition (PVD) titanium nitride (TiN) coated AISI416 stainless-steel. SN Appl Sci 1(11):1420

18. Elumalai $V$ et al (2019) Preparation of tungstic acid functionalized titanium oxide nanotubes and its effect on proton exchange membrane fuel cell. SN Appl Sci 1(4):348

Publisher's Note Springer Nature remains neutral with regard to jurisdictional claims in published maps and institutional affiliations. 